\section{An investigation of amphetamine anorexia under three motivational conditions of free feeding*}

\author{
SHERWOOD O. COLE \\ Rutgers University, Camden, N.J. 08102
}

Male rats were administered a free-feeding test under one of nine combined conditions of amphetamine $(0.0,0.5,1.0 \mathrm{mg} / \mathrm{kg})$ and food deprivation $(0,24$, $48 \mathrm{~h}$ ). Overall results demonstrated a significant drug effect and deprivation effect on feeding. Further analysis of the drug's action under each of the motivational conditions demonstrated that the depressant effect of amphetamine was generalized over the range of motivational conditions studied and that the pattern of the dose-response function was quite similar.

The general depressant effect of amphetamine on feeding behavior is well established (Cole, 1967). Evidence suggests that this effect holds over a fairly wide range of conditions of feeding motivation (defined experimentally by percentage of free-feeding body weight) under operant schedules of procuring food (Gollub \& Mann, 1969; Meginniss, 1967). However, little or no evidence is available on the general nature of this depressant effect on free-feeding behavior under different conditions of feeding motivation.

The purpose of the present study was to investigate the depressant effect of amphetamine on free-feeding behavior under three conditions of feeding motivation (defined by specific hour of food privation) to determine the generality of the drug's action.

\section{SUBJECTS}

Thirty-six 120-day-old male rats of the Charles River strain served as Ss. They were housed in individual plastic cages in a temperature-controlled laboratory and were allowed ad lib access to laboratory chow except when under testing conditions. Water was available to $\mathrm{Ss}$ at all times throughout the study.

\section{PROCEDURE}

The Ss were assigned randomly to one of three d-amphetamine sulfate conditions $(0.0,0.5$, or $1.0 \mathrm{mg} / \mathrm{kg})$ and to one of three food-deprivation conditions $(0,24$, or $48 \mathrm{~h})$ to form nine independent groups of four Ss each. All Ss were administered a single 1-h test period in the home cage under these conditions, with food

*This research was supported by a faculty fellowship from the Rutgers University Research Council and was conducted while the author was visiting investigator at the Laboratory of Psychobiology and Psychopharmacology, Rome, Italy, during the academic year 1971-72. Appreciation is expressed to Professors $D$. Bovet and $A$. Oliverio for their assistance in making this study possible. consumption and water consumption being measured. The general procedure for the testing of a $\mathrm{S}$ was as follows. After the appropriate number of immediately preceding hours of food deprivation, the $\mathbf{S}$ was removed from the cage, weighed, injected IP with the appropriate dose of amphetamine, and returned to the cage. The $0-\mathrm{mg} / \mathrm{kg} \mathrm{Ss}$ received a controlled-volume injection of physiological saline. Forty minutes later, the test period was begun.

Food consumption was measured by weighing a ceramic cup containing dry-ground laboratory chow before placing it in the cage at the beginning of the test period, weighing it again at the end of the test period, and taking standard deviation of the groups. the difference in weight (corrected for spillage) as the amount consumed. Water consumption was measured in milliliters by means of standard units on the water bottles.

\section{RESULTS}

The food consumption for the nine independent groups under the combined amphetamine and food-deprivation conditions is summarized in Fig. 1. Overall analysis of these results yielded a significant drug effect $\left(\mathrm{F}^{*}=10.19\right.$, df $=2 / 27$, $\mathrm{p}<.01)$ and a significant deprivation effect $(F=15.92, \mathrm{df}=2 / 27, p<.01)$, but no significant Drug by Deprivation interaction $(F<1.00)$. Overall analysis of water consumption for the nine independent groups under the combined amphetamine and food-deprivation conditions indicated no significant drug effect, deprivation effect, or Drug by Deprivation interaction. In all three instances, the " $F$ " values were less than 1.00 .

A further analysis of the data ${ }^{1}$ within each of the conditions of feeding motivation demonstrated a similar pattern of drug effect. For $0 \mathrm{~h}$ of food deprivation, an orthogonal comparison of the control group $(0.0 \mathrm{mg} / \mathrm{kg})$ with the combined drug groups $(0.5+1.0 \mathrm{mg} / \mathrm{kg})$ yielded a significant difference $(\mathrm{F}=32.67, \mathrm{df}=$ $1 / 9, \quad p<.01)$, but the difference between drug groups was not significant $(\mathrm{F}=2.00, \mathrm{df}=1 / 9$, $\mathrm{p}>.05)$. For $24 \mathrm{~h}$ food deprivation,

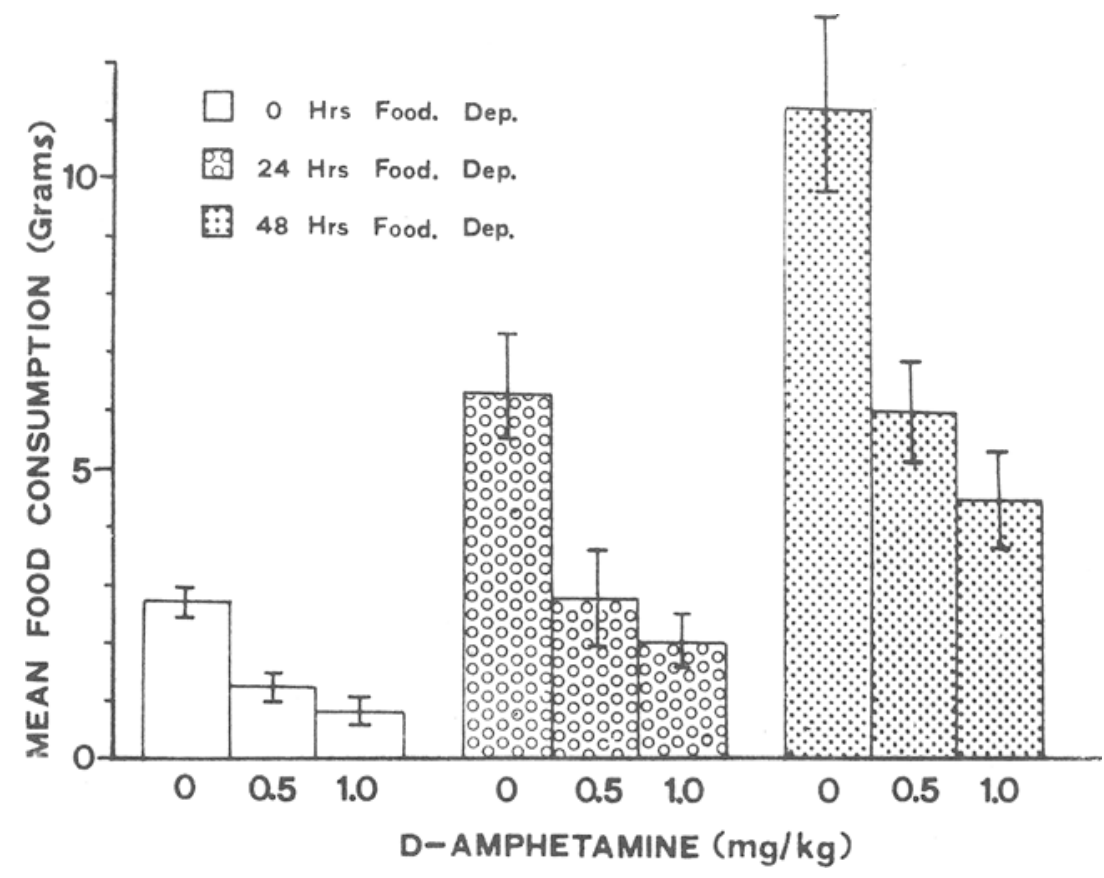

Fig. 1. Mean food consumption for groups of male rats under combined conditions of amphetamine and food deprivation. The vertical lines represent the 
orthogonal comparisons indicated a significant difference between the control group and the combined drug groups $(\mathrm{F}=16.75, \mathrm{df}=1 / 9, \mathrm{p}<.01)$ but no significant difference between drug groups $(F<1.00)$. For $48 \mathrm{~h}$ of food deprivation, orthogonal comparisons of the control group with the combined drug groups demunstrated a significant difference $(F=18.90, \mathrm{df}=1 / 9, \mathrm{p}<.01)$, but, again, the difference between drug groups was not significant $(F<1.00)$. DISCUSSION

The general depression of feeding behavior by amphetamine found in the present study is consistent with previously reported findings of an anorexic effect of the drug (Cole, 1967). Although the contribution of peripheral mechanisms to such an effect of the drug should not be minimized, evidence suggests that amphetamine anorexia is mediated by central sites in the hypothalamus (Cole, in press). The failure to find a significant general interaction effect of amphetamine and food deprivation on feeding in the present study is not consistent with previous findings of such an effect in a continuously reinforced operant task (Cole \& Gay, 1971) and does suggest that the specific requirements of the feeding task (free feeding vs operant) are important to the demonstration of such an effect. The absence of a significant drug effect or deprivation effect on water consumption in the present study is not surprising in light of the fact that the Ss had continuous access to water throughout the study. Water consumption was measured merely as a means of more accurately assessing the effect of experimental conditions on feeding.

The more detailed analysis of the anorexic action of the drug under the three different conditions of feeding motivation demonstrates some additional facts of interest concerning amphetamine's effect in a free-feeding situation. First, even in the absence of specific hours of food deprivation $(0 \mathrm{~h})$, the drug's action was statistically reliable in spite of the fact that the drug control Ss $(0 \mathrm{mg} / \mathrm{kg})$ ate considerably less under this condition than did the drug control Ss under 24 and $48 \mathrm{~h}$ of food deprivation. Contributing to this statistically significant effect of the drug was the fact that the variability within the groups was considerably less under $0 \mathrm{~h}$ of food deprivation than it was under 24 and $48 \mathrm{~h}$ of food deprivation (see Fig. 1). Secondly, although the mean food consumption for the $1.0-\mathrm{mg} / \mathrm{kg}$ group was less than that for the $0.5-\mathrm{mg} / \mathrm{kg}$ group under all three conditions of feeding motivation, this difference did not approach statistical significance under any condition.

The similarity in the pattern of drug effect under the conditions of food motivation investigated in the present study suggests that the depressant action of amphetamine on feeding in a free-feeding situation is generalized over a fairly wide range of motivational conditions and that the nature of the dose-response function (while not linear) is quite stable over such a range of conditions. These findings should provide some guidelines for the designing of studies where amphetamine and free-feeding are an integral part of the experimental design.

\section{REFERENCES}

COLE, S. O. Experimental effects of amphetamine: A review. Psychological Bulletin, 1967, 68, 81-90.

COLE, S. O. Hypothalamic feeding mechanisms and amphetamine anorexia. Psychological Bulletin, in press.

COLE, S. O., \& GAY, P. E. Interaction of amphetamine and food deprivation on a food-motivated operant. Communications in Behavioral Biology, Part A, 1971, 6, 345-347.

GOLLUB, L. R., \& MANN, W. G., JR. The interaction of amphetamine and body weight on a food-reinforced operant. Psychopharmacologia, $1969,15,64-75$. MEGINNISS, R. F. Interaction of d-amphetamine and food deprivation on fixed ratio behavior of pigeons. Psychological Reports, 1967, 20 , 355-358.

\section{NOTE}

1. The author acknowledges the capable assistance of Patricia E. Gay in this analysis. 